\title{
Human Computer Interface for Wheelchair Movement
}

\author{
Assist. Prof. Dr. Rana Fareed Ghani Hani Saeed Hassan
}

Department of computer science, University of Technology, Baghdad, Iraq.

\author{
Received 19/7/2016 \\ Accepted 17/10/2016
}

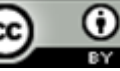

This work is licensed under a Creative Commons Attribution 4.0 International License

\begin{abstract}
:
This paper aims to develop a technique for helping disabled people elderly with physical disability, such as those who are unable to move hands and cannot speak howover, by using a computer vision; real time video and interaction between human and computer where these combinations provide a promising solution to assist the disabled people. The main objective of the work is to design a project as a wheelchair which contains two wheel drives. This project is based on real time video for detecting and tracking human face. The proposed design is multi speed based on pulse width modulation(PWM), technique. This project is a fast response to detect and track face direction with four operations movement (left, right, forward and stop). These operations are based on a code written in MATLAB environment and Arduino IDE environment. The proposed system uses an ATmega328microcontroller (Arduino UNO board).
\end{abstract}

Key words: Movement Wheelchair, Human Computer Interaction, Assisting Disable People.

\section{Introduction:}

Human computer interface/interaction (HCI) also called Man-Machine interface or Interaction (HCI) is automatically emerged with the rise of computers. The HCI term consists of three parts, the first is human (humen), the second is computer (devices) and the third is interface, a point where the human can tell the computer what to do[1].Basically the $(\mathrm{HCI})$ is a field of exploration and exercise invented in the late 1970s and mid 1980s [2]. In 1980s, graphical user interface (GUI) is developed it is the interface that is intended for the less difficult fathoming of the clients of the PCs. In 1990s communitarian works are developed and the Internet that allows interchanges among individuals got to be less complex, as a consequence, numerous new advances. In 2000s Personal Development Assistance (PDA) was invented, it is commonly used in the present world. [3]

Recently; the (HCI) is utilized as a part of range of Cognitive Science. With the assistance of the therapeutic offices, internet can be supplied remotely. In recent years, the industry has occupied the entire systems and strategies, for example, video procedure to manage diverse operations, as in the, connection of PC with human, storing, controlling, recording and process utilizing a PC $[3,4]$. The video comprises a succession of frames designed to video structure, 
which can be taken by moving cameras. Development should be possible by items and camera movement before the camera, continuously. With the last after; effect of these moves different picture rates have been taken in pictures successions, for example, in film material around 24,25 and $30 \mathrm{~Hz}$, and video normally in 50 and $60 \mathrm{~Hz}$. Human eye needs 30 frames per second (fps), which is the most reduced rate required for the effective blends every video frame is composed of easily moving image[5].

Nowadays, robots interact closely with a combination of humans in their everyday environment in area leisure, health care, nursing, entertainment, help disabled people. The number of people with disabilities has significantly increased in these day [6]. There are many researches concerned with the wheelchair that helps disabled people. Murai, et al.[7] (2009), proposed "Elevator Available Voice Activated Wheelchair", presenting a functional voice activated wheel chair, and presenting design for helping disable people who have difference to speak. This work is based on microphone for input sound, PC computer for characterizing voice command. The circuit with sensors for the wheelchair it controlled by peripheral interface controller (PIC). This framework has two noteworthy tasks. The primary task is the crash evasion work that the wheelchair maintains a strategic distance from the divider, walls and obstruction. These advantages are based on the sensor data. This task has three independent motions of the stop motion, shirking motion and deceleration motion. The second task is the strong lift passage/exit capacity which can work easily in an assortment of circumstances. After the above is executed, this framework cannot help all disabled people who do not have ability to speak. In contrast to proposed system.
Qidwai, et al. [8] (2010), proposed "Arabic Speech-Controlled Wheelchair". They Present design of a speech-controlled wheelchair using a joystick type control of an electronic wheelchair which is almost impossible. This work is based on microphone for input Arabic command, PC computer for characterizing voice command. Finally, this work is not suitable for people who do not have ability to move fingers and cannot speak. Patil, et al. [9] (2014), design the "Wheelchair Using Finger Operation with Image Processing Algorithms". They present design for helping disabled people who have ability to move fingers. This work is based on image processing and Alf and Vegard RISC processor (AVR) microcontroller for controlled wheelchair. They drive their wheelchair through finger operation using image processing by figure detection and recognition based on conversion of finger image from RGB to HSV. Indeed, the process indicates getting pixels of nose region for face tracking. This design accommodates some disabled people who can move their fingers and do not accommodate persons who have been subjected to an accident in the upper hands and fingers and lower limbs. Buvanswari et, at. [10] (2015), designed "Eye Scrutinized Wheelchair for People Affected with Tetraplegia". This work introduces a wheel seat framework for the general population influenced by Tetraplegia. The wheelchair which is chosen here utilizes the Baughman's calculation and relies upon the way of the eye to send orders to the microcontroller to control the wheel seat in all directions and stops the motion. Also, Arduino board receives orders from PC computer for controlling wheelchair direction.

In this paper the video surveillance is used with the interaction between human and computer. These combination provides a promising 
solution to help disabled people through interaction between disabled people and computer via real time video thus helping a disable people, elderly such as those who are unable to moves hand and cannot speak.

\section{HCI}

The human computer interaction (HCI) system consists of several parts that are essential to the design of such systems. The human part should always consider what humans contemplate and necessitate what physical skill restrictions they may have how systems are negotiable, what they find attractive and fun when they use computers. When humans interact with computers, they check the meeting lifetime experience. Designers must decide how to make the products appealing without dispersing users from their duties. The computer part consists of computer or microcomputer such as Arduino Atmel ATmega328 for special purpose and sophisticated device interact with human. The interface part isa point where two objects meet. Interaction occurs between humans and computers. The human interaction includes both software and hardware. People should use computers or embedded devices which are different for different purposes, so they have to interact with these devices. Researchers have built different interfaces and methods for those programmers and designers find a reasonable balance between what can be programmed within schedule and budget, and would be ideal for humans. Face detection and tracking are an essential part in computer vision as it becomes pervasive in many research in the past but now wide range in different form. Recently, most of automated cameras can distinguish objects and remarkably stand up before taking a photo. Furthermore, this is extremely helpful in video observing or human computer interaction [11].Image base and feature base are two face detection approaches to detect a facial part in the given image. Feature based techniques have some focal points which are pivot independent, scale freedom, and their execution time is so fast, in contrast with different techniques[12].

Face detection technique is separated into three classifications: low level analysis, feature analysis and active shape model, all these techniques are able to distinguish between a face and numerous different objects. It finds faces by separating basic components like eyes, nose and mouth[13].Paul Viola and Michael Jones propose viola jones face detection algorithm which is a fast feature analysis technique. Many researchers use this technique which causes fast detection of face with accuracy[14]. In face tracking is a computer methodology whose goal is to keep the indication of similar distinguished faces inside a video sequence [15]. This technique is divided into three classifications first: point tracking, second: kernel based tracking and third: silhouette based tracking. The goal of the first track technique includes detection in every frame whereas the second and the third techniques include detection exactly when the object first appears in the scene[16].Cam-shift algorithm is one of the techniques based on second classification; kernel based trackers. Cam-shift is mean-shift algorithm improvement for a head and face tracking applications because the mean-shift uses fix window size. Camshift algorithm by Bradski's is adaption of the mean-shift for tracking. CAMA Shift algorithm is used as an essential fragment of other applications such as human computer interaction $[17,18]$.

\section{Proposed System}

Our proposed system consists of two parts detecting direction and movement wheelchair based on real time video that 
isshown in Fig. (1). Firstly, detecting direction part consists of five stages (face detection, crop face, conversion color space, extract hue channel from HSV color spaceand tracking the distinguished face). Face detection is the first stage that is based on the viola jones face detection technique where the current frame enters to this stage and detects human face by viola jones technique then insert bounding rectangle for distinguished face and then calculation mass center by using equation (1). Crop face is the second stage, after inserting bounding rectangle for the distinguished face cropping this bounding rectangle. In other words, we get a face image. Conversion of color space, is the third stage, in this stage the current frame is converted from RGB to HSV color space. This step supports the next stage. The fourth stage is extracting hue channel from the HSV color space because of hue channel which contains more information about skin. Fifth stage consists of two steps (detecting nose region and tracking based on bright pixels from hue channel).The last part of this stage is detecting direction of human that uses our system by applying CAMA Shift algorithm. Initial hue channel pixels of the nose region are to this algorithm. Secondly, movement part is the responsible part for the moving of wheelchair. This part is based on coordinator software, it is a code written by Arduino IDE for the movement wheelchair. To achieve this part, MATLAB sends orders to the Arduino UNO board for every certain moment (current frame).These orders, are coordinates ( $\mathrm{x}$ and $\mathrm{y}$ ) of the mass center. An Arduino receives orders from the MATLAB via universal serial bus(USB) connection and then Arduino checks if the mass center coordinates when to lie in the center region of the screen and then supplying a different voltage to two-wheel drive D.C motors based on face direction (top, bottom, left and right) and then control output voltage by using PWM technique. Working of our proposed system can be understood by the following flowchart shown in Fig.(2).

$$
\operatorname{cent}(\mathrm{x})=\operatorname{bbox}(1)+(\operatorname{bbox}(3) / 2), \operatorname{cent}(\mathrm{y})=\operatorname{bbox}(2)+(\operatorname{bbox}(4) / 2) \ldots
$$

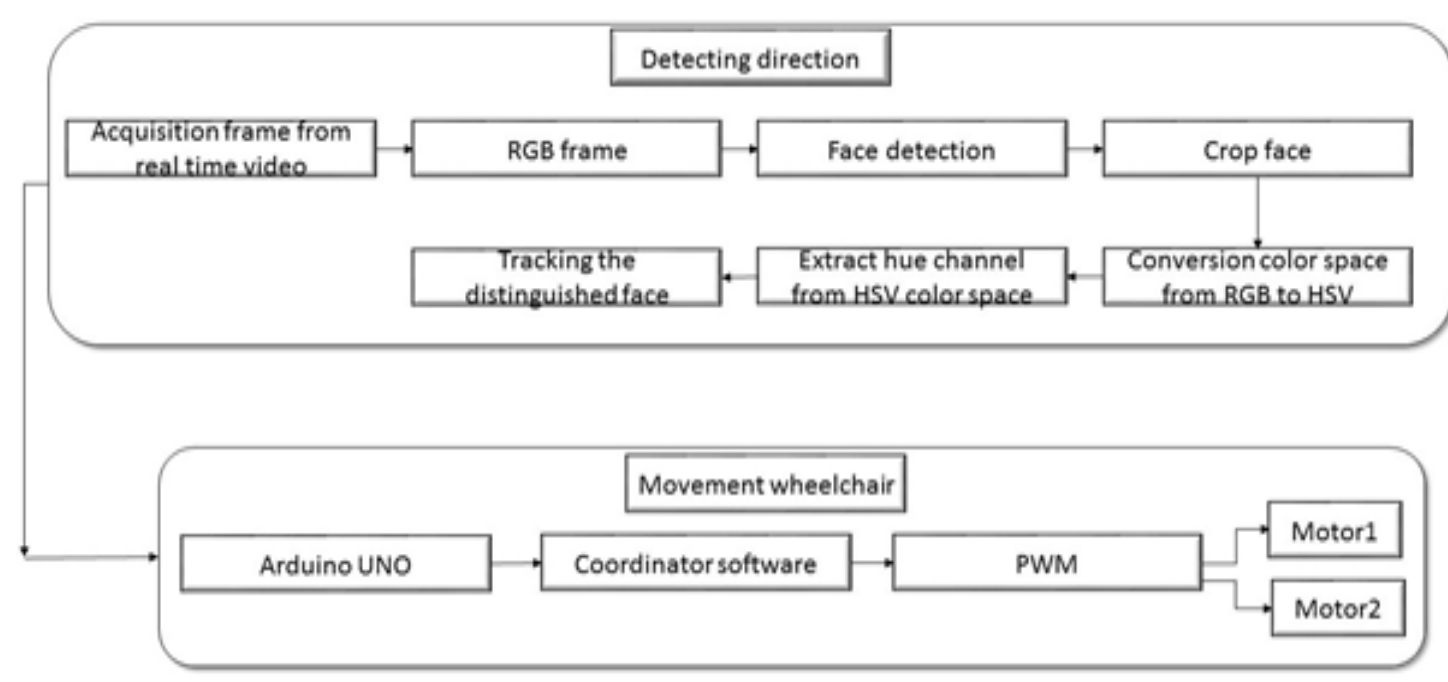

Fig. (1) Proposed System Diagram 


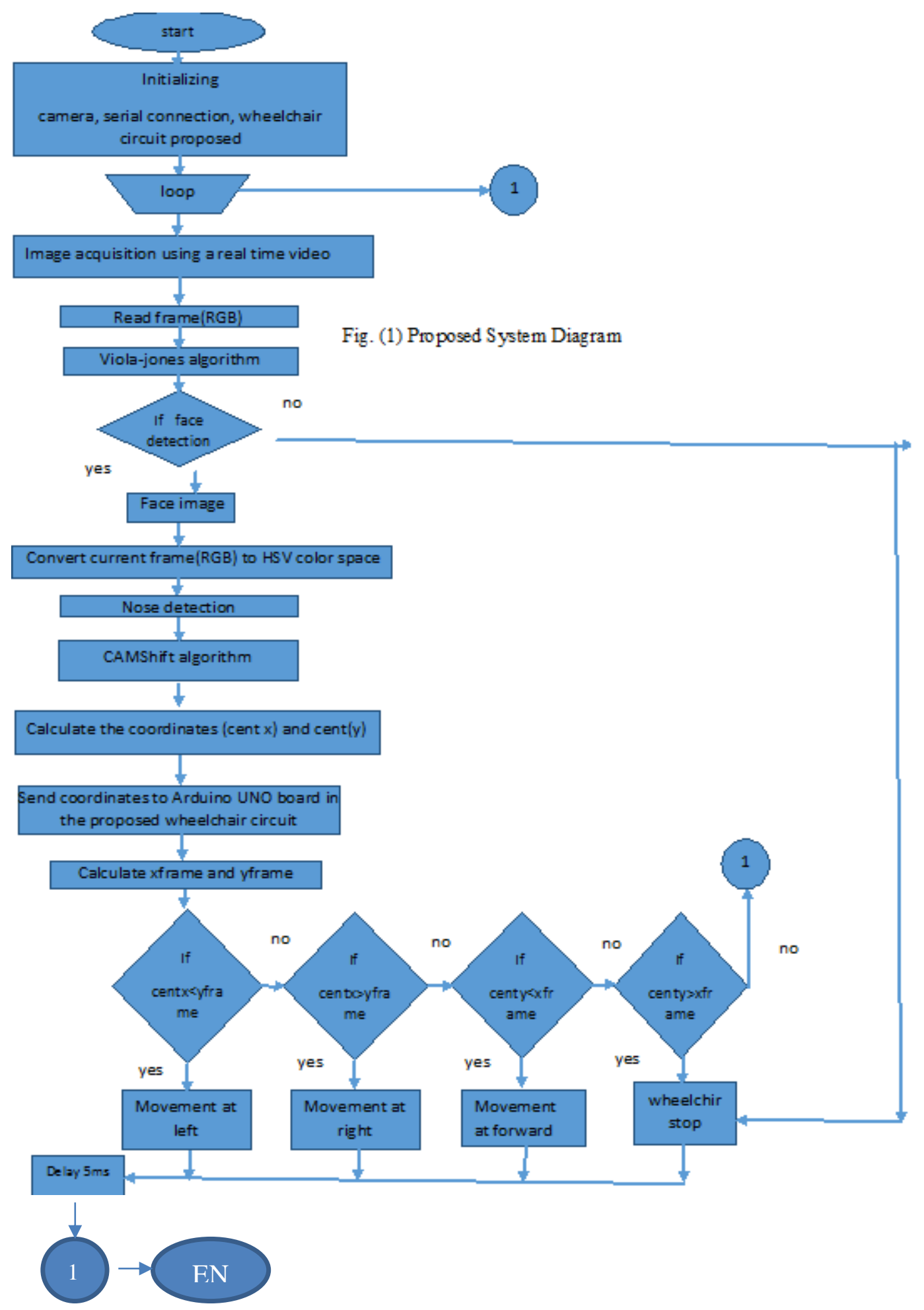

Fig. (2)Flowchart for Wheelchair Movement proposed 


\section{Results}

After developing the whole system, testing is made of proposed wheelchair and its communication with Arduino UNO and fixed video camera (real time video) that has resolution of $160 * 120$. The camera must be far away from face, roughly $30 \mathrm{~cm}$. our system has been tested by 20 frames. The results below describe these processes.

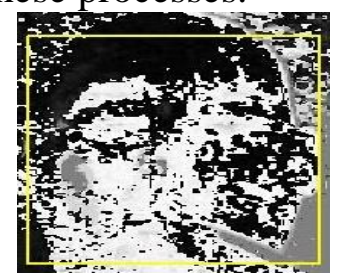

Fig. (3) Extracted Hue Channel from HSV Color
Fig. (3) shows the Hue channel pixels are extracted from HSV color space of the distinguished face (current frame (RGB)).This conversion is needed for the getting Hue channel pixels that have more information about skin. These pixels and the nose region are input to the CAM Shift algorithm. In other words, bright pixels that are determined by nose region, are use. To track the motion of a human face by using CAM Shift algorithm

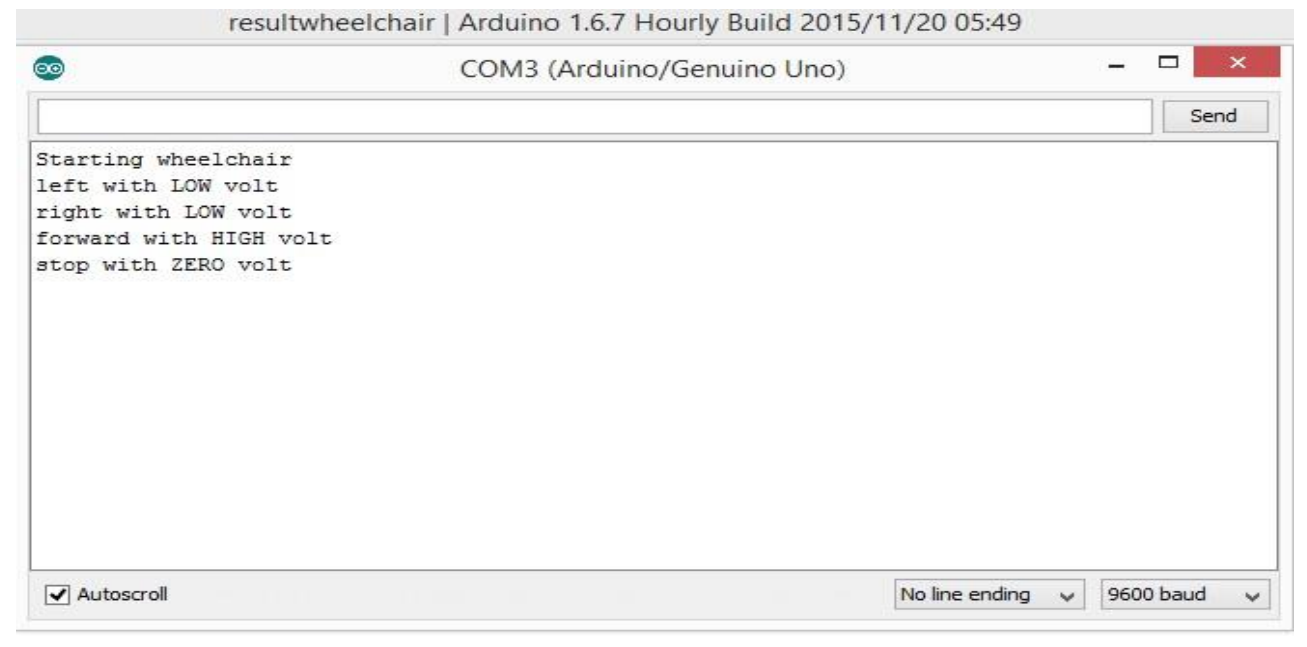

Fig. (4) Execution Result in Arduino IDE Environment

Fig. (4) above shows the execution result in Arduino IDE environment, supplying a different voltage to two-wheel drive D.C motors by using PWM technique based on face direction.

Fig. (5) chart explains the relation between speed of the wheelchair movement and direction of the wheelchair. The accuracy criterion for this chart is based on percentages of the supplyied voltage between $(0 \%$ and $100 \%$ ) and movement of the wheelchair(forward,left,right and stop). In other words, (zero volt $(0 \%)$ ), (low volt (20\%)) and (high volt (100\%)). Supplying a different voltage to twowheel drive for the wheelchair is based on face direction (top, bottom, left and right).Output voltage is conrolled by using the PWM technique 


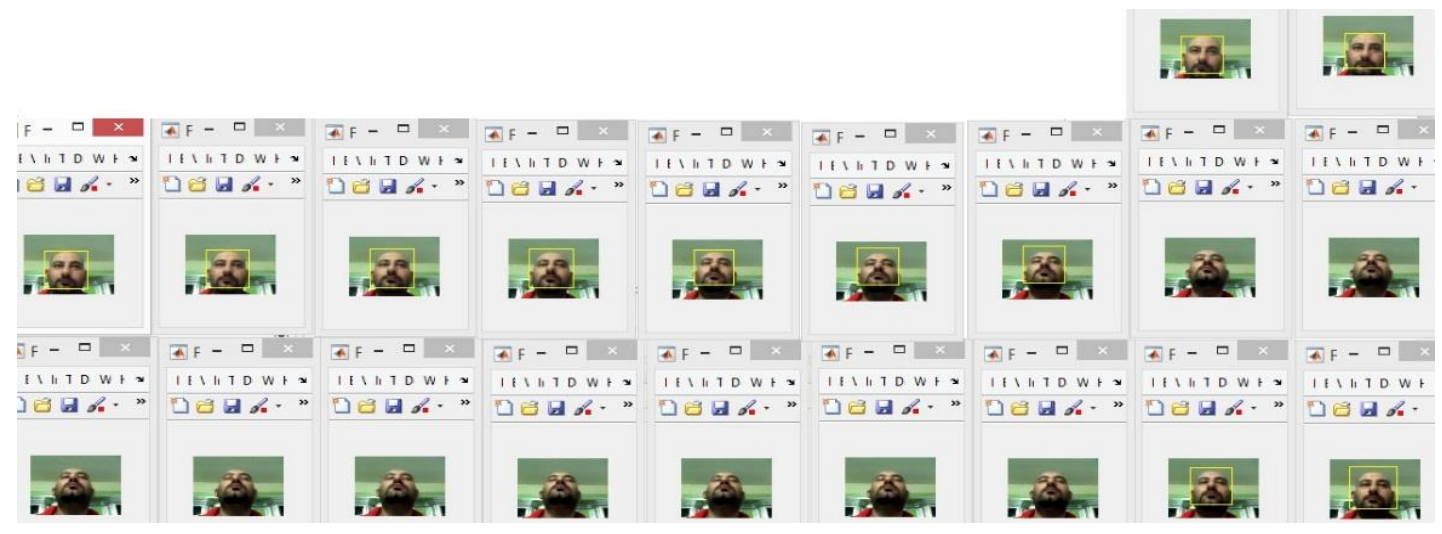

Fig. (6)The Frames in Case of Forward Movement

Fig. (6) shows all cases when the human head moves to top. Thus, moving the bounding rectangle to the top means, the wheelchair is moving forward.

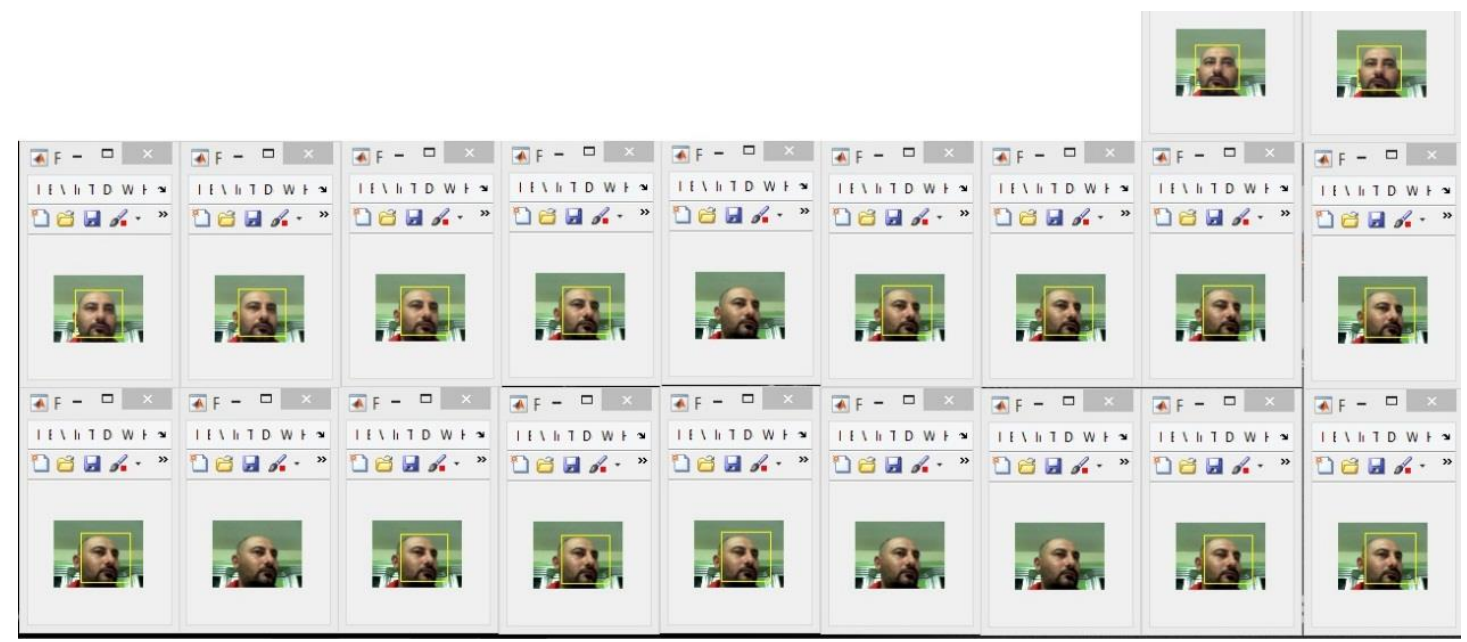

Fig. (7) The Splitting Frames of Real Time Video in Case of Right Movement.

Fig. (7) shows all cases when the human head moves to right. Thus ,moving the red rectangle to the right. That means the wheel chair is moving to the right.

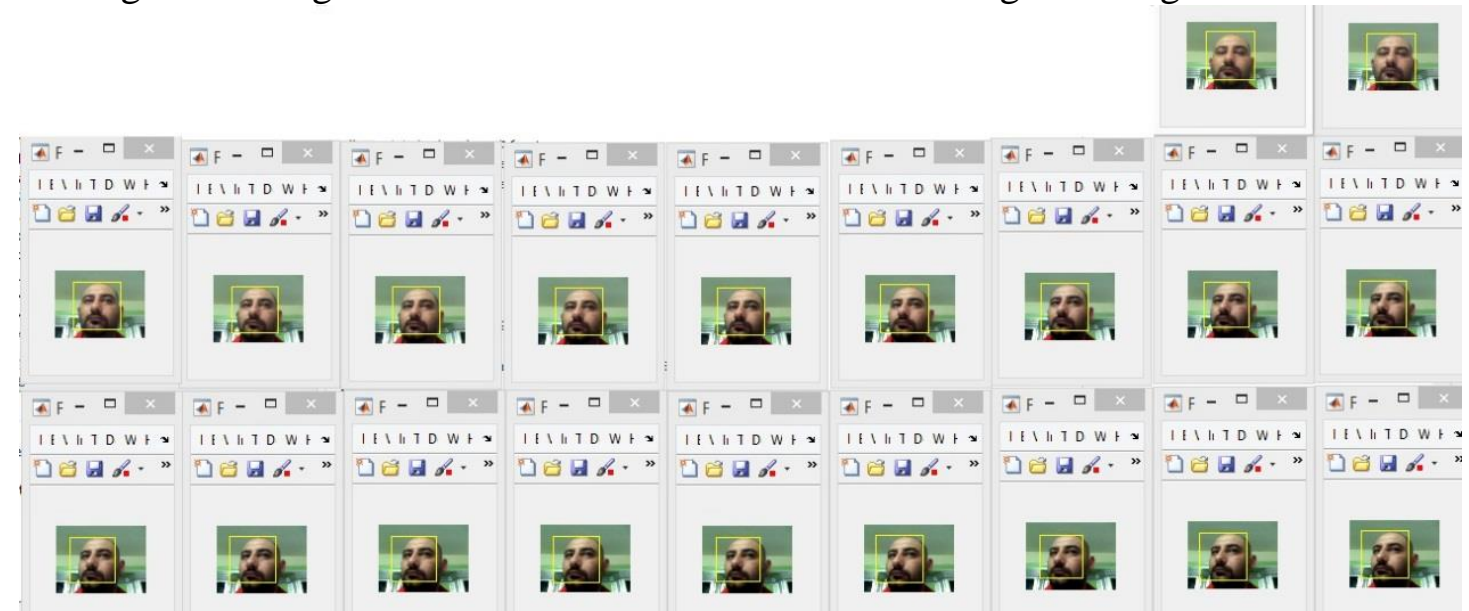

Fig. (8) The Frames in Case of Left Movement.

Fig. (8) shows all cases when the human head moves to the left, Thus, moving the red rectangle to the left. That means the wheelchair is moving to the left. 


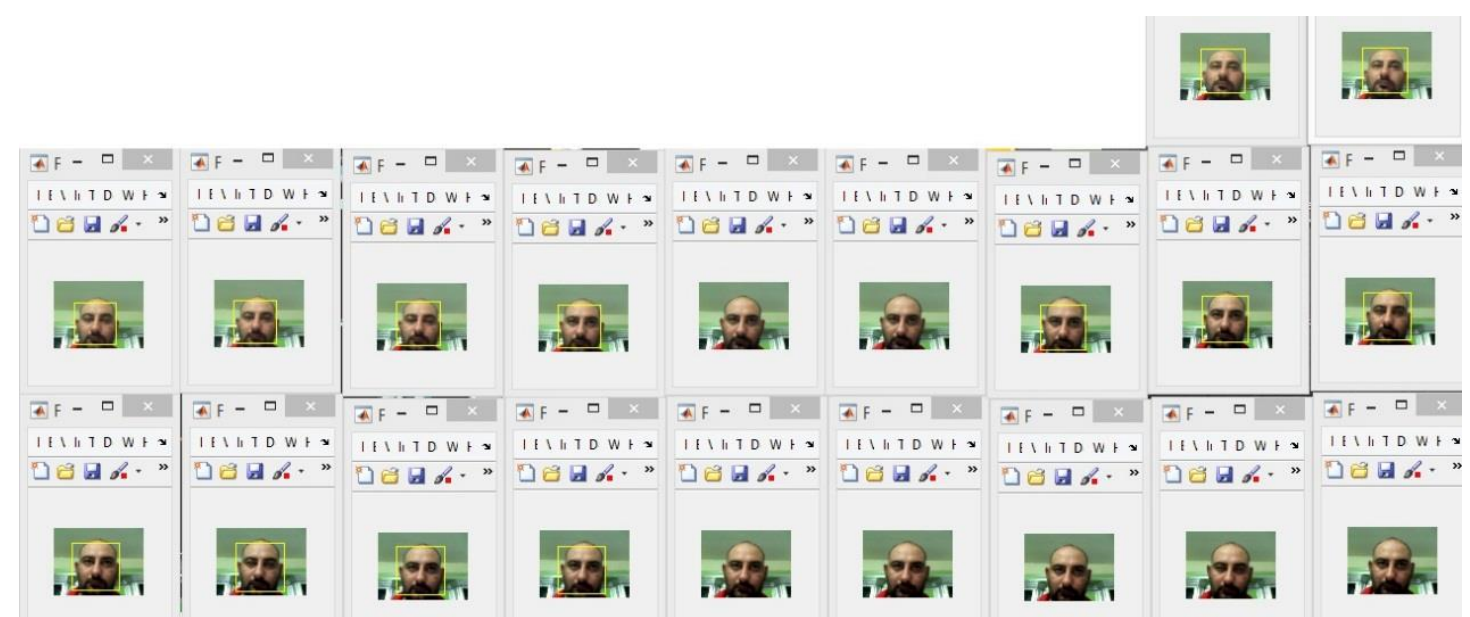

Fig. (9) TheFrames in Case the Movement Stops.

Fig. (9) shows all cases when the human head moves down,thusmoving the red rectangle down, that mean the wheel chair has stopped.

Table (1) Wheelchair Movement and Direction.

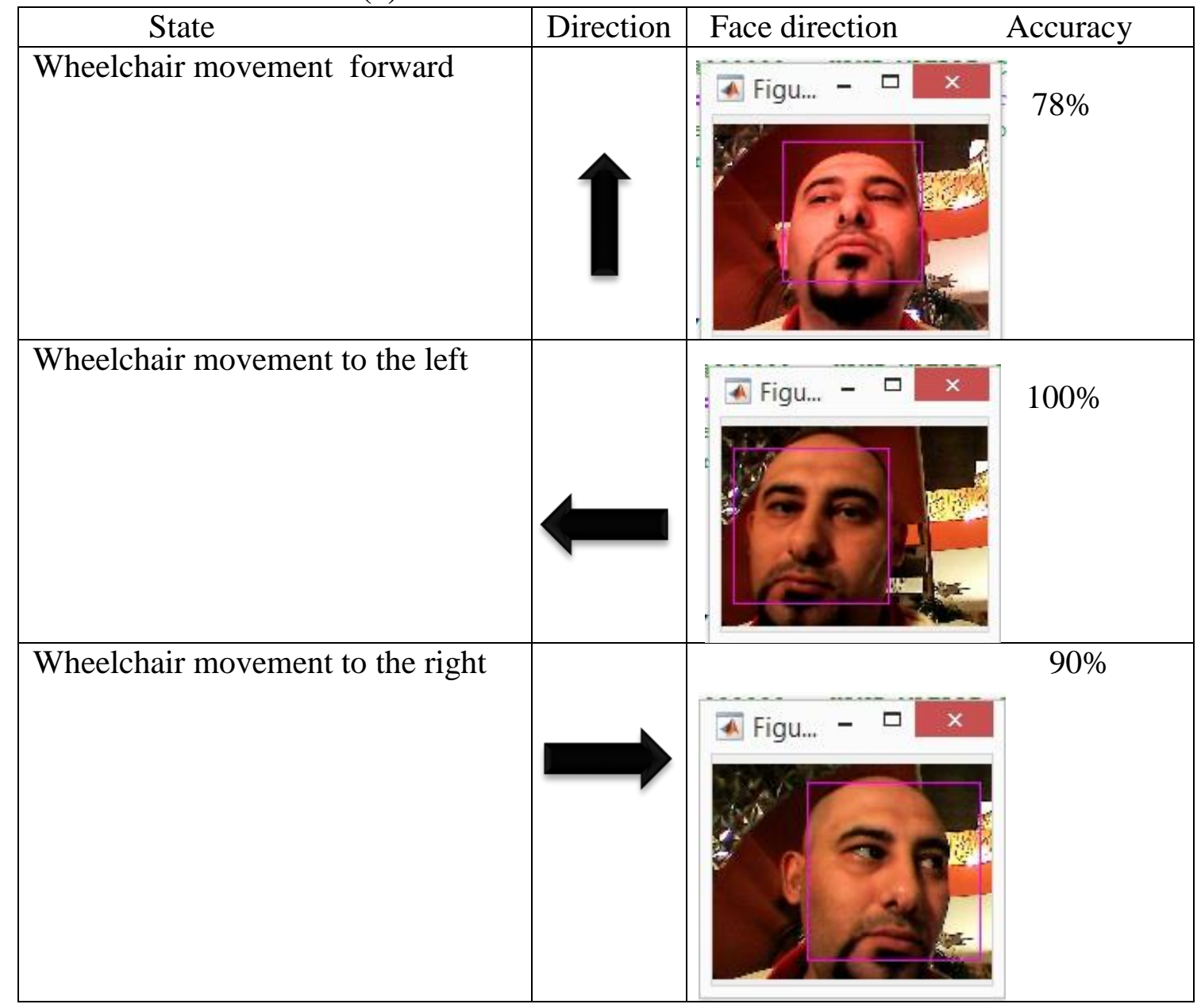




\begin{tabular}{|l|l|l|}
\hline $\begin{array}{l}\text { Wheelchair stop.in this steps } \\
\text { wheelchair can stop for a long time } \\
\text { when the face is logout from the } \\
\text { camera through down facial } \\
\text { movements }\end{array}$ & Stop
\end{tabular}

Table (1) above shows accuracy functions of the proposed system calculated by equation (2)

Accuracy $=(($ true detect + true movement $) /($ true detect + true movement + false detect + false movement $)) * \%$

where,

true detect $=$ number of frames thatis have rectangle bounding false detect $=$ reverse the true detect true movement $=$ number of frames that achieved for the movement of the wheelchair false movement= reverse the true movement to the accurate calculation for the stopped wheelchair that is illustrated in figure (9). true detect $=13$, true movement $=20$, false detect $=7$ and false movement $=0$. By Applying equation (2) the accuracy result $=83 \%$

\section{Conclusion:}

The main aim of our proposed system is the interaction between human and computer by detecting a human face, tracking it and accordingly setting digital pin of Arduino UNO stop, low or high. By using of MATLAB, face detection algorithm and CAM Shift algorithm have been developed with the technique of thresholding. RGB component of any human face is read and accordingly threshold values are set which eventually make detecting direction a bright spot and background black. Taking this bright spot into consideration, an algorithm for wheelchair movement is developed and successfully implemented on an Arduino UNO using USB and video camera.

\section{References:}

[1] Karray, F.; Alemzadeh, M. A.; Saleh, J.; Arab, M. 2008. HumanComputer Interaction. International Journal on Smart Sensing and Intelligent systems, 1(1):137-138.

[2] Rick, J.; Horn, M.; Maldonado, R. M. 2013. Human-Computer Interaction and the Learning. sciences CSCL Proceedings, 2(1): 451-452.

[3] Macknzie, I. S. 2013. Human Computer Interaction. Elsevier Inc, $15 \mathrm{P}$.

[4] Jameel, N.; Alfatly, E. K. J. 2008. Video Image for Security System Using Chaotic Oscillator. M.Sc. dissertation, Department of Computer Science, University of Technology, pp5-7.

[5] Chellappa, R.; Veeraraghavan, A.; Aggarwal, G. 2005. Pattern Recognition in Video, University of maryland, paper, USA.

[6] Chhabria, S. A.; Dharaskar, R. V. 2011. Multimodal Interface for Disable Persons. International Journal of Computer Science and Communication, 2(1): 223-225.

[7] Murai, A.; Mizuguchi, M.; Saitoh, T.; Osaki, T. 2009. Elevator available voice activated wheel chair. IEEE International Symposium Robot and 
Human Interactive Communication, 5(3):730-733.

[8] Qidwai, U.; Ibrahim, F.2010. Arabic speech-controlled wheelchair. Information Sciences Signal Processing and their Applications (ISSPA), International Conference, pp: 153-155.

[9] Pati, C.; Gharge, S; Modhave, S.; Angal, Y. S. 2014. Design of Wheelchair Using Finger Operation With Image Processing Algorithm. International Journal of Research in Engineering and Technology, 3 (2): 232-237.

[10] Buvanswari, B.; Kalpalatha, T. 2015. Eye Scrutinized Wheelchair For People Affected With Tetraplegia. International Journal of Computer Science, Engineering and Information Technology,5(2):15-71.

[11] Zahra, K. 2013. Techniques for Real-time Multi-person Face Tracking for Human-robot Dialogue. M.Sc. dissertation, Blekinge Institute of Technology, School of Engineering.

[12] Hu, W. C.; Yang, C. Y.; Huang, D. Y. 2011. Feature-based Face Detection Against Skin-Color Like Backgrounds with Varying Illumination. Journal of Information
Hiding and Multimedia Signal Processing,2(2): 123-125.

[13] Hatem, H.; Zou, B.; Majeed, R. 2015.A Survey of Feature Base Methods for Human Face Detection. International Journal of Control and Automation, 8(5):70-72.

[14] Fedrik, M. 2014. Face Detection Approache. International Journal of Innovative Research in Science, Engineering and Technology, 3(4):107-109.

[15]Guxi, D. C. Real-Time Face Tracking Methodes. 2009. PhD. thesis,Carnegie Mellon University.

[16] Himani, S.; Parekh, D. G. T.; Udesang, K. J. 2014. A Survey on Object Detection and Tracking Methods. International Journal of Innovative.Research in Computer and Communication Engineering, 2(2):68.

[17] Hidayatullah, P. 2010. Color in Informatics and Media Technology. MSc. dissertation, University Jean Monnet Saint-Etienne.

[18] Feng, G. 2015. The Reviewe of The Camshift Algorithm and its Improved Algorithm of Target tracking. Researchin International Journal of Research in Engineering and Science, $3(8): 1-3$. 
تذاخل الانسان والحاسوب من اجل حركة الكرسي المتحرك

هاني سعيد حسن

$$
\begin{aligned}
& \text { أ.م.د. رنـا فريـد غني } \\
& \text { قسم علوم الحاسوب، الجامعة التكنلوجية، بغداد، العراق. }
\end{aligned}
$$

هذا البحث تهدف الى تطوير تقنية لمساعدة المسنين ذوي الإعاقة الجسدية، مثل أولئلك الذين هم غير قادرين

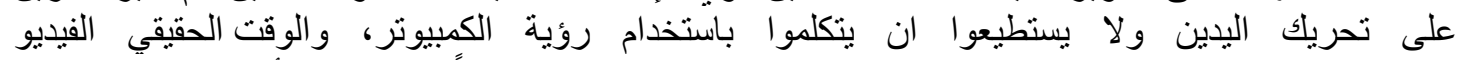

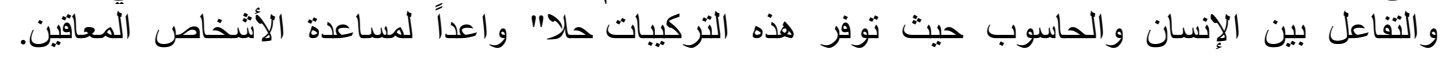

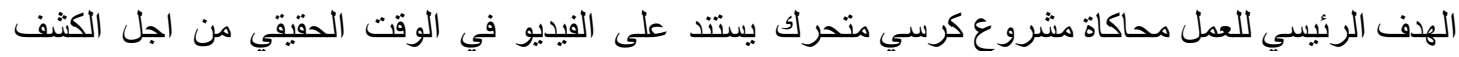

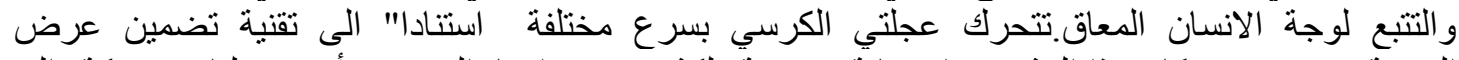

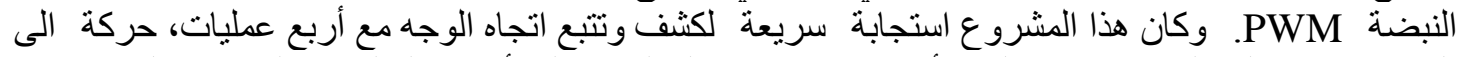

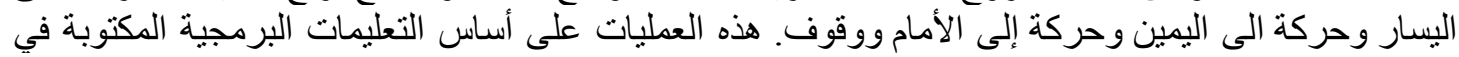

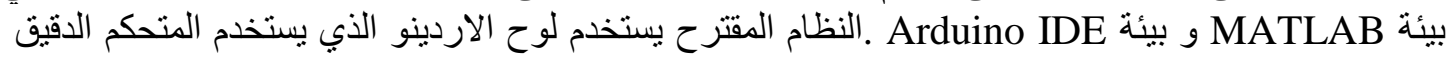

.ATmega 328

الكلمات المفتاحية: تفاعل الانسان و الكومبيوتر ، حركة الكرسي المتحرك، و مساعدة المعوقين. 